\title{
Influence of Electrolyte Temperature on Anodic Oxidation of Single Crystalline Silicon in Ethylene Glycol Solution
}

\author{
Masamitsu YUGA, ${ }^{a *}$ Masanori OHYAMA, ${ }^{b}$ and Manabu TAKEUCHI ${ }^{c}$
}

\author{
${ }^{a}$ Graduate School of Science and Engineering, Ibaraki University (4-12-1 Nakanarusawa, Hitachi, Ibaraki 316-8511, \\ Japan) \\ ${ }^{b}$ Department of Electrical Engineering, Tokyo National College of Technology (1220-2 Kunugida-cho, Hachioji-shi, \\ Tokyo 193-0997, Japan) \\ 'Department of Electrical and Electronic Engineering, Ibaraki University (4-12-1 Nakanarusawa, Hitachi, Ibaraki 316- \\ 8511, Japan)
}

Received November 2, 1999 ; Accepted March 22, 2000

\begin{abstract}
Anodic oxidation of single crystalline silicon was carried out in constant current and constant voltage modes using a solution of $0.04 \mathrm{~N} \mathrm{HNO}_{3}$ in an ethylene glycol at temperatures of 20 to $70^{\circ} \mathrm{C}$. The current and voltage between an anode and a cathode were measured during the anodic oxidation process. The influence of anodic oxidation temperature on the growth process of silicon dioxide films was studied by current-time characteristics. The silicon dioxide films grown on silicon wafers were analyzed by XPS to study the influence of the electrolyte temperature and hydroxides content. The transition time when the voltage between the anode and cathode reaches the preset-up voltage had a maximum value at $45^{\circ} \mathrm{C}$. The silicon dioxide film thickness and capacitance had a maximum and minimum, respectively, when the anodization was carried out at $45^{\circ} \mathrm{C}$. Stoichiometric $\mathrm{SiO}_{2}$ films could not be formed at this temperature. The XPS peak intensities of $\mathrm{Si}^{4+}$ and $\mathrm{Si}^{0+}$ in anodically oxidized films depended on the electrolyte temperature. The $\mathrm{Si}^{4+}$ peak appeared even in the substrate for the films anodized at $45^{\circ} \mathrm{C}$. It was confirmed that the boundary region existed between the $\mathrm{SiO}_{2}$ film and $\mathrm{Si}$ substrate. Furthermore, hydroxides existing within the film was concentrated at the silicon dioxide-silicon boundary at $45^{\circ} \mathrm{C}$. The property of oxide films depends on the content of hydroxide, which is a function of the anodization temperature.
\end{abstract}

Key Words : Anodic Oxidation, Single-crystalline Silicon, Ethylene Glycol, X-ray Photoelectron Spectroscopy (XPS)

\section{Introduction}

Growth of silicon dioxide $\left(\mathrm{SiO}_{2}\right)$ film is a basic technique for integrated circuit technology. Usually, thermal oxidation process of silicon is carried out in a horizontal reactor at a high temperature over $1100^{\circ} \mathrm{C}$. However, application of the thermal oxidation technique to device fabrication is limited, because it needs a high temperature. For example, hydrogen bonds in amorphous silicon are cut off over $400^{\circ} \mathrm{C}$. A high temperature is not required to an anodic oxidation technique. ${ }^{1)}$ However, there have been a few reports on anodic oxidation of single crystalline silicon, ${ }^{2,3)}$ because thermally oxidized silicon films are generally superior in quality to anodically oxidized films. Particularly the influence of electrolyte temperature on anodic oxidation process of silicon has scarcely been reported, although it was examined in GaAs. ${ }^{4}$ )

We studied the growth of $\mathrm{SiO}_{2}$ films by anodic oxidation on Si wafers at around room temperatures and found that the quality of the $\mathrm{SiO}_{2}$ films were considerably influenced by the electrolyte temperature previously. ${ }^{5}$ ) This paper describes the influence of temperature on the oxide film growth in the anodic oxidation of single crystalline silicon at low temperatures. The quality of the anodically oxidized films will be discussed based on the results of XPS analysis.

\section{1 Anodic oxidation}

\section{Experimental}

The automatic monitoring system for the anodic oxidation is shown in Fig. 1, in which details of the anodic oxidation cell and the electrodes used in this study are illustrated. The cell was placed in a water bath, which is provided with a heater to control the temperature. The anode was an n-type single crystalline silicon wafer, whose resistivity was $10 \Omega \mathrm{cm}$. The cathode was a platinum plate, whose purity was $99.9 \%$. The silicon wafer was clung on the hollow holder by vacuum pumping with a trap. The electrolyte used in this study was a solution of $0.04 \mathrm{~N} \mathrm{HNO}_{3}$ in an ethylene glycol. The electrolyte temperature was kept constant in the range of from $20^{\circ} \mathrm{C}$ to $70^{\circ} \mathrm{C}$. When a constant current was fed to the electrode by a DC power supply, a silicon dioxide film began to grow on the silicon wafer, and the thickness of oxide film increased with the elapse of time. The voltage and current between the anode and cathode were measured during the anodic oxidation process every ten seconds. The voltage in a standard resistance of $100 \Omega$ was converted into the current. Both the voltage and current measured by a digital voltmeter were transferred to a personal computer through a GP-IB interface cable. When the voltage reached $200 \mathrm{~V}$, the constant current mode was changed to the constant voltage electrolysis, 


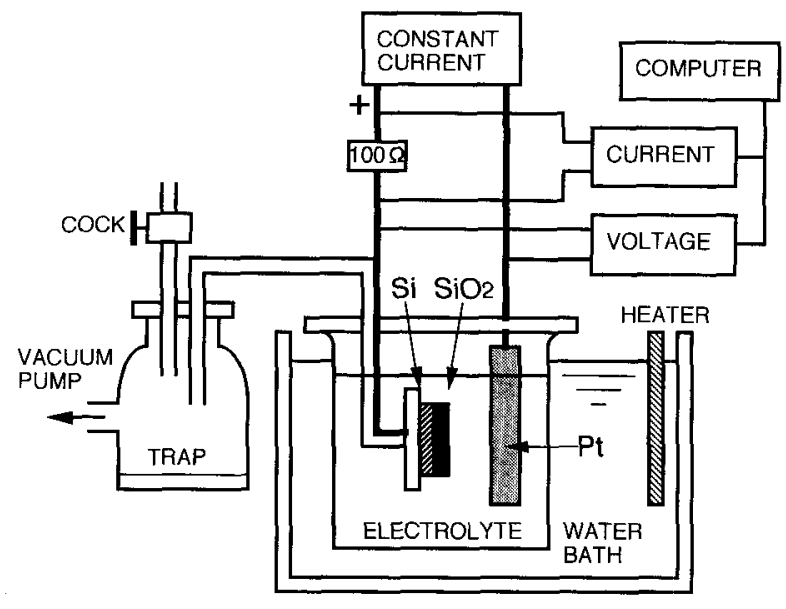

Fig. 1 The automatic measuring system of anodic oxidation process used in this study, and the cell configuration.

in which the current decreased with elapse of time, and the surface of silicon dioxide film was found to become smooth.

\section{2 XPS analysis}

XPS analysis of $\mathrm{SiO}_{2}$ film on $\mathrm{Si}$ substrate was carried out under the pressure of less than $10^{-7} \mathrm{~Pa}$. The silicon dioxide film thickness and internal hydroxide contents were measured by the XPS depth profile. The surface of sample was sputtered by argon ions at $20 \mathrm{mPa}$ to obtain the profile. It was confirmed that the depth of one sputter cycle was constant by the measurement of the standard sample. The observation was made on the $\mathrm{SiO}_{2}$ film surface by using a CCD camera during the XPS analysis. The experimental condition of XPS analysis is summarized in Table 1. Finally, MOS structures were fabricated based on the silicon dioxide films by vacuum depositing an aluminum electrode of $1.23 \mathrm{~mm}^{2}$ in area, and the capacitance of $\mathrm{SiO}_{2}$ films was measured to study the effect of the electrolyte temperature on the $\mathrm{SiO}_{2}$ thickness.

\section{Results and Discussion}

\section{1 Current-time characteristics}

The change in current and voltage with the anodic oxidation time of the $\mathrm{Si}$ wafer at the electrolyte temperature of $35^{\circ} \mathrm{C}$ is given in Fig. 2, where the anodic oxidation begun at a constant current density of $100 \mathrm{~mA} \mathrm{~cm}{ }^{-2}$ and the preset-up voltage was $200 \mathrm{~V}$. In the constant current electrolysis, the voltage between the anode and cathode increased with an increase in thickness of growing $\mathrm{SiO}_{2}$ film and reached the preset-up voltage, and then the anodic oxidation was changed to the constant voltage electrolysis, where the current decreased with elapse of time. The time when the voltage between the anode and cathode reaches the preset-up value of $200 \mathrm{~V}$ and the current begins to decrease is defined as transition time in this

Table 1 The experimental condition for XPS analysis.

\begin{tabular}{|c|cccc|}
\hline \multirow{2}{*}{ X-ray } & Filament & $\mathrm{h} v$ & Voltage & Power \\
\cline { 2 - 5 } & $\mathrm{Mg}$ & $1253.6 / \mathrm{eV}$ & $14 / \mathrm{kV}$ & $400 / \mathrm{w}$ \\
\hline \multirow{2}{*}{ Sputter } & Beam & Emission & Pressure & Interval \\
\cline { 2 - 5 } & $3 / \mathrm{kV}$ & $25 / \mathrm{mA}$ & $20 / \mathrm{mPa}$ & $30 / \mathrm{s}$ \\
\hline
\end{tabular}

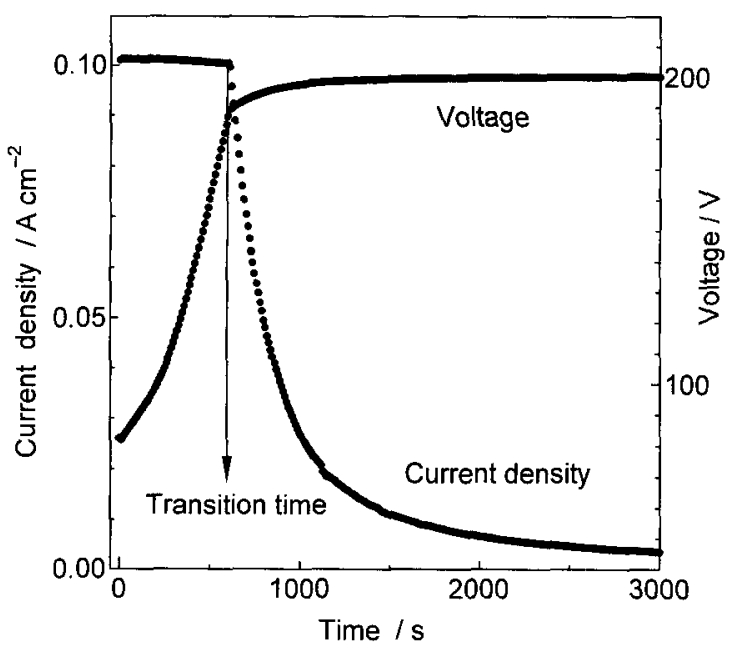

Fig. 2 Changes in current density and voltage with anodic oxidation time of $\mathrm{Si}$ at $35^{\circ} \mathrm{C}$.

paper. As described above, the electrolysis mode was changed from constant current to constant voltage at the transition time.

The current-time characteristics of the anodic oxidation are given in Fig. 3 for four choices of electrolyte temperature of $40,45,50$ and $60^{\circ} \mathrm{C}$ at current densities of 50 and $100 \mathrm{~mA} \mathrm{~cm}{ }^{-2}$. In general, the transition time was long in the anodization at low current densities in comparison with high current densities. The transition time depended on the electrolyte temperature and was the longest at $45^{\circ} \mathrm{C}$ for both the current densities. Similar results were also obtained by the current interrupting method $^{6)}$ on the analysis of anodic oxidation process of single crystalline silicon. These results suggest that oxidation process at $45^{\circ} \mathrm{C}$ may be different from those at other temperatures.

\section{2 XPS spectra of Si2p and 01s}

To study the anodic oxidation of $\mathrm{Si}$ at $45^{\circ} \mathrm{C}$ in more detail, internal chemical states of the oxide films were analyzed by XPS with argon ions sputtering. XPS analysis was carried out every $30 \mathrm{~s}$ of sputtering. The depth profiles of the $\mathrm{SiO}_{2}$ film on $\mathrm{Si}$ substrate by XPS analysis are shown in Fig. 4 for three choices of anodic oxidation at

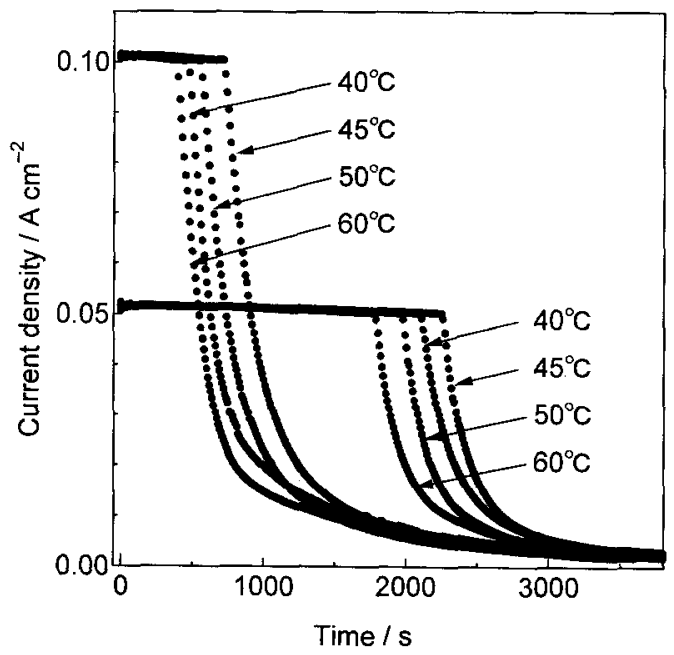

Fig. 3 Changes in current density with anodic oxidation time of $\mathrm{Si}$ at $40,45,50$ and $60^{\circ} \mathrm{C}$. 
the electrolyte temperatures of 40,45 and $50^{\circ} \mathrm{C}$ for 1 hour anodization. The ordinate and abscissa in the figure indicate the depth and the binding energy, respectively. The zero point on depth axis corresponds to the surface of the specimen. The height indicates the photoelectron counts. The photoelectron counts of the O1s peaks are referred to Fig. 6. The boundary between the $\mathrm{SiO}_{2}$ and Si substrate was located at the depth of about $100 \mathrm{~nm}$ for all the specimens. The right two peaks are Si2p spectra, $\mathrm{Si}^{4+}$ corresponds to $\mathrm{SiO}_{2}$, whose binding energy is about $108 \mathrm{eV}$, and the other peak $\mathrm{Si}^{0+}$ originates from single crystalline $\mathrm{Si}$, whose binding energy is about $100 \mathrm{eV}$. The left peak is O1s, whose binding energy is about 538 $\mathrm{eV}$.

The growth rate of oxide films in thermal oxidation was reported. ${ }^{7,8)}$ To compare the anodic oxidation with thermal oxidation, thermal oxidation of a $\mathrm{Si}$ wafer with the same resisitity was carried out at $1100^{\circ} \mathrm{C}$ for 3 hours in dry $\mathrm{O}_{2}$ in this study, and the XPS analysis was made on the formed film. Results for the thermally oxidized specimen is also given at the top of Fig. 4. In the thermal oxidation, the $\mathrm{Si}^{4+}$ peak intensity was approximately constant up to the boundary from the surface and decreased rapidly associated with an increase in $\mathrm{Si}^{0+}$ peak intensity in the $\mathrm{Si}$ substrate. In contrast to the thermal oxidation of $\mathrm{Si}$, the $\mathrm{Si}^{4+}$ peak intensity did not decrease so rapidly associated with an increase in $\mathrm{Si}^{0+}$ peak intensity beyond the boundary for the anodic oxidation at $40^{\circ} \mathrm{C}$. This tendency was more predominant, the $\mathrm{Si}^{4+}$ peak intensity did not decrease even beyond $100 \mathrm{~nm}$ for the anodic oxida-

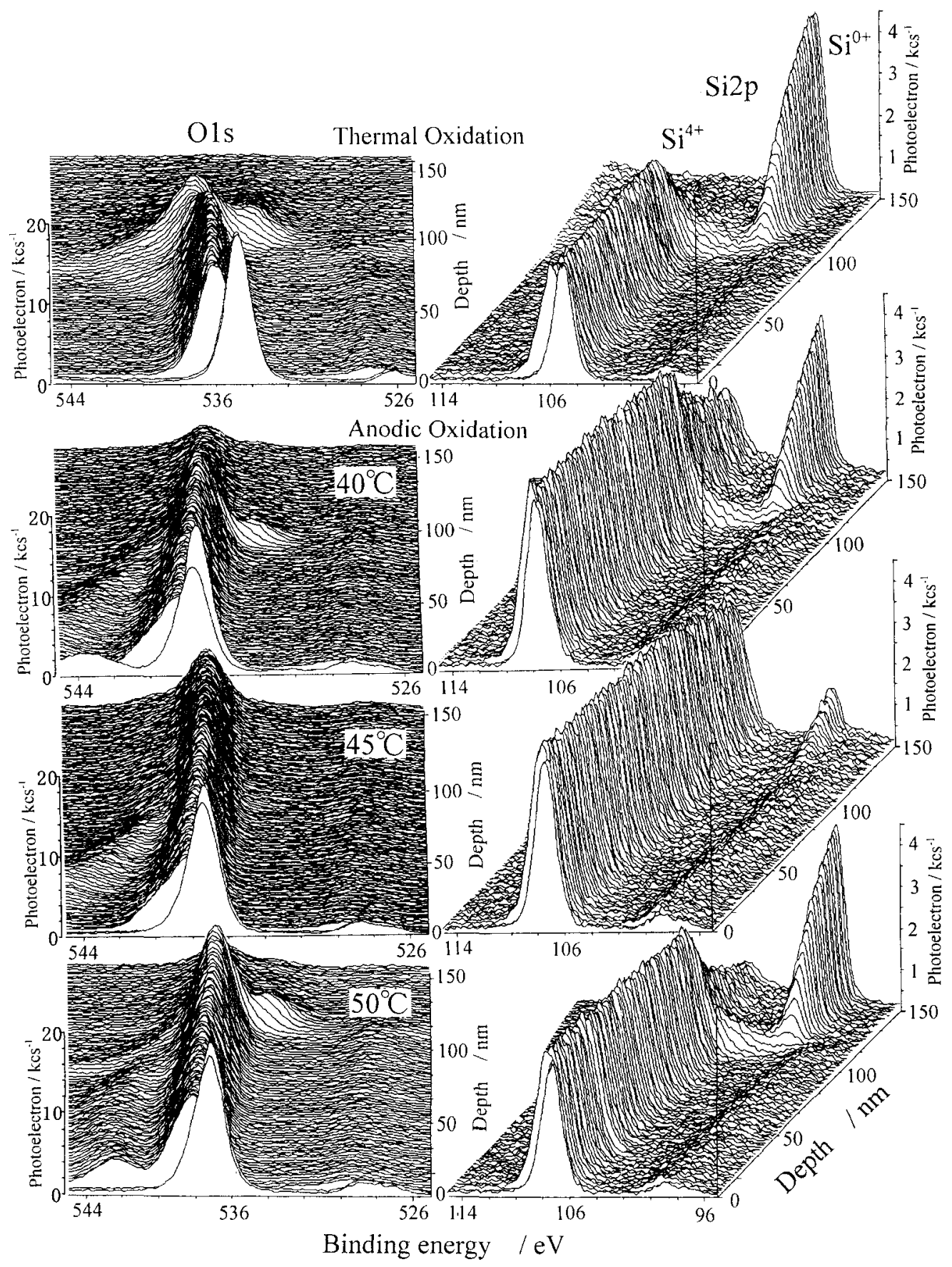

Fig. 4 Depth profiles of $\mathrm{S}^{0+}, \mathrm{Si}^{4+}$ and O1s spectra by XPS analysis for specimens thermally oxidized at $1100^{\circ} \mathrm{C}$ and anodically oxidized at 40,45 and $50^{\circ} \mathrm{C}$. 
tion at $45^{\circ} \mathrm{C}$, where the $\mathrm{Si}^{0+}$ peak began to increase but not so strongly. However, the $\mathrm{Si}^{4+}$ peak intensity decreased rapidly and the $\mathrm{Si}^{0+}$ peak intensity increased strongly beyond the boundary for the anodic oxidation at $50^{\circ} \mathrm{C}$, which were close to the results of the thermal oxidation.

On the other hand, change in depth profiles of the O1s at $538 \mathrm{eV}$, shown at the left side of Fig. 4, with the electrolyte temperature was similar to that of the $\mathrm{Si}^{4+}$ peaks, though the peak intensity was about five times of that of the $\mathrm{Si}^{4+}$ peaks. Change in the $\mathrm{Si} 2 \mathrm{p}$ and $01 \mathrm{~s}$ peaks with electrolyte temperature suggests that the anodic oxidation film formed at $45^{\circ} \mathrm{C}$ is the thickest among the three films formed at various temperatures at the same oxidized time. The O1s peak intensity was high at the surface for all the specimens, which can be attributable to oxygen adsorption on the surface. The small peak at round $529 \mathrm{eV}$ is a satellite peak by $\mathrm{Mg}-\mathrm{K} \beta$, and the other small peak at around $542 \mathrm{eV}$ may be hydroxide or moisture in the anodically oxidized film.

\section{3 Depth profiles of XPS analysis}

Depth profiles of $\mathrm{Si}^{0+}$ and $\mathrm{Si}^{4+}$ are shown in Fig. 5 for the thermal and anodic oxidation. The zero point on the abscissa indicates the surface of a specimen. The concentration of $\mathrm{Si}^{0+}$ increased sharply around $100 \mathrm{~nm}$ and the concentration of $\mathrm{Si}^{4+}$ decreased sharply simultaneously in the thermal oxidation specimen. This result suggests that the thickness of the thermally oxidized layer is determined by the rising point of $\mathrm{Si}^{0+}$ concentration and the falling point of $\mathrm{Si}^{4+}$ in Fig. 5, where the thickness is about $100 \mathrm{~nm}$. In Fig. 5, $\mathrm{Si}^{0+}$ of a small quantity which exists in the oxidized film consists of mostly a satellite peak and the back ground. Therefore, Si which was not oxidized through the anodization process may not be remained in the anodically oxidized film. Although the $\mathrm{Si}^{0+}$ and $\mathrm{Si}^{4+}$ concentrations begin to increase and decrease in the anodic oxidation respectively, at approximately the same depth as the thermal oxidation, the boundary of $\mathrm{Si}$ and $\mathrm{SiO}_{2}$ is not so unambiguous as that except for the anodic oxidation at $50^{\circ} \mathrm{C}$ and $60^{\circ} \mathrm{C}$. The decrease of $\mathrm{Si}^{4+}$ and the increase of $\mathrm{Si}^{0+}$ in the anodic oxidation are not so sharp comparing with those in the thermal oxidation. The boundary of the $\mathrm{SiO}_{2}$ film on $\mathrm{Si}$ substrate is not definite any more in the anodic oxidation at $40^{\circ} \mathrm{C}$. In other words, the boundary between the $\mathrm{SiO}_{2}$ film and $\mathrm{Si}$ substrate is ambiguous in the anodic oxidation at $40^{\circ} \mathrm{C}$. This result suggests that considerable amount of oxygen diffuse into the $\mathrm{Si}$ region and anodize $\mathrm{Si}$ existing in the boundary territory for the anodic oxidation at $40^{\circ} \mathrm{C}$.

Further diffusion of $\mathrm{Si}^{4+}$ was confirmed for the anodic oxidation at $45^{\circ} \mathrm{C}$ as shown in Fig. 5(d). The boundary region broadened most widely at $45^{\circ} \mathrm{C}$. The existence of excess oxygen was confirmed by the quantitative analysis from the comparison of $\mathrm{O} 1 \mathrm{~s}$ and $\mathrm{Si}^{4+}$ peak area at this temperature. In this case, stoichiometric $\mathrm{SiO}_{2}$ film was not formed because of excess oxygen. The excess oxygen influences the insulating properties of the film. As a result, the film insulation becomes improper in the anodic oxidation at $45^{\circ} \mathrm{C}$. However, the boundary became clear again in the anodic oxidation at over $50^{\circ} \mathrm{C}$ as shown in Figs. 5(e) and (f). Because of deterioration of insulating ability of $\mathrm{SiO}_{2}$ insulation, the transition time when the voltage reaches the preset-up value becomes long where the thickest oxide film is formed at $45^{\circ} \mathrm{C}$.

Depth profiles of the peak intensity of main $\mathrm{O} 1 \mathrm{~s}$ peak and $\mathrm{O} 1 \mathrm{~s}$ originated from oxygen in the hydroxide are shown in Fig. 6 for the anodic oxidation at various temperatures. In Fig. 6, the main peak at about $538 \mathrm{eV}$ is originated from the oxygen bound with $\mathrm{Si}$, while the peak at $542 \mathrm{eV}$ from the oxygen of hydroxide. The $\mathrm{O} 1 \mathrm{~s}$ peak located at the $\mathrm{SiO}_{2}-\mathrm{Si}$ boundary is sharp except for the anodic oxidation at $45^{\circ} \mathrm{C}$, and the $\mathrm{O} 1 \mathrm{~s}$ intensity decreases rapidly in the $\mathrm{Si}$ substrate. The peak intensity of the part of hydroxide is smaller than those of O1s, and the depth profile of the hydroxide intensity changes obviously with electrolyte temperature. The O1s peak intensity in the oxide films was constant for the thermal oxidation, and any trace of hydroxide peaks did not appear as shown in Fig. 4. The sum of the intensities of main O1s peak and O1s originated from oxygen in hydroxide becomes constant for the anodic oxidation and without excess oxygen. On the other hand, the sum is not constant at the boundary of the $\mathrm{SiO}_{2}$ film and $\mathrm{Si}$ substrate, which suggests existence of excess oxygen in the films.

When the anodic oxidation at 30 and $35^{\circ} \mathrm{C}$ proceeds, the hydroxide is distributed uniformly inside the $\mathrm{SiO}_{2}$ film. When the electrolyte temperature rises to $40^{\circ} \mathrm{C}$, however, the distribution of hydroxide begins to lean around the $\mathrm{SiO}_{2}-\mathrm{Si}$ boundary. This result suggests that stoichiometric $\mathrm{SiO}_{2}$ films can not be formed, because the reaction proceeds so rapidly ${ }^{9,10)}$ at the vicinity of the boundary. The activation energy for reaction changes suddenly ${ }^{6}$ ) at the temperature, and excess oxygen is formed, resulting in deterioration of insulating properties of the film. Particularly at $45^{\circ} \mathrm{C}$, the hydroxides are concentrated only vicinity the boundary, and no hydroxide appear at the surface as shown Fig. 6(d). If oxygen does not perfectly bind with $\mathrm{Si}$, excess oxygen may disturb ion movement. Usually the resistance of $\mathrm{Si}$ decrease with an increase in temperature, but it increases temporarily in such a case. ${ }^{6)}$ This condition relates to the increase in film thickness at $45^{\circ} \mathrm{C}$. Furthermore, the amount of hydroxide is small for the anodization at $45^{\circ} \mathrm{C}$. When much water is contained in the electrolyte, the growth ratio of the anodically oxidized films becomes small. ${ }^{11)}$ The electrolyte used in this experiment did not contain any water. However, the film capacity increased when water was contained in the electrolyte. In addition, the capacity of films formed in an electrolyte with some water decreased when water was removed by the annealing at over $300^{\circ} \mathrm{C}$. These results indicate that the hydroxide in the film promotes the increase in film thickness. Because the amount of hydroxide is small at $45^{\circ} \mathrm{C}$, the thickness of a $\mathrm{SiO}_{2}$ film is larger than those anodized at other temperatures. In other words, changes in both the oxide film thickness and the transition time with electrolyte temperature depend on both the total amount and distribution of hydroxide in the film. The reaction rate decreases at higher than $50^{\circ} \mathrm{C}$ and the hydroxide distribution becomes uniform again as shown in Figs. 6(e) and (f). 
Such change in oxidation behavior occurred in the anodic oxidation at $45^{\circ} \mathrm{C}$ did not appear in amorphous $\mathrm{Si}$ formed the current interrupting method. ${ }^{12)}$ The specific oxidation behavior of $\mathrm{Si}$ at $45^{\circ} \mathrm{C}$ may be correlated with crystallinity of $\mathrm{Si}$, although the detailed mechanism is

Thermal oxidation

(a)

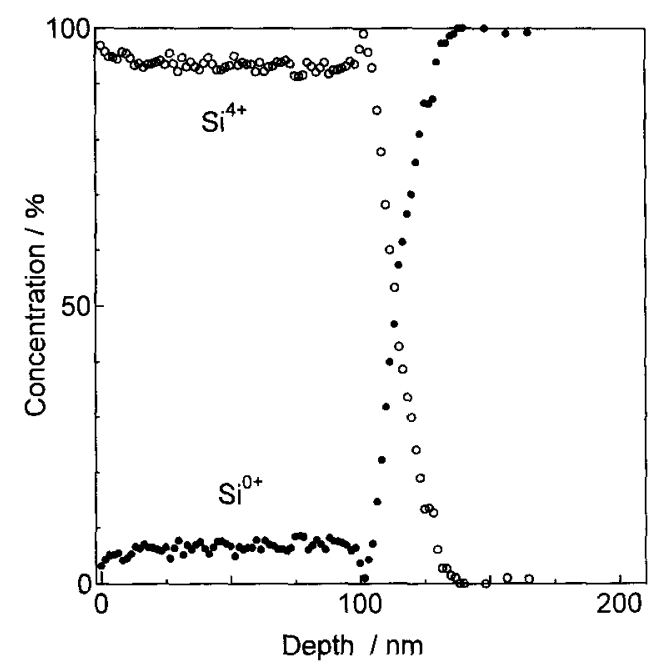

$40^{\circ} \mathrm{C}$

(c)

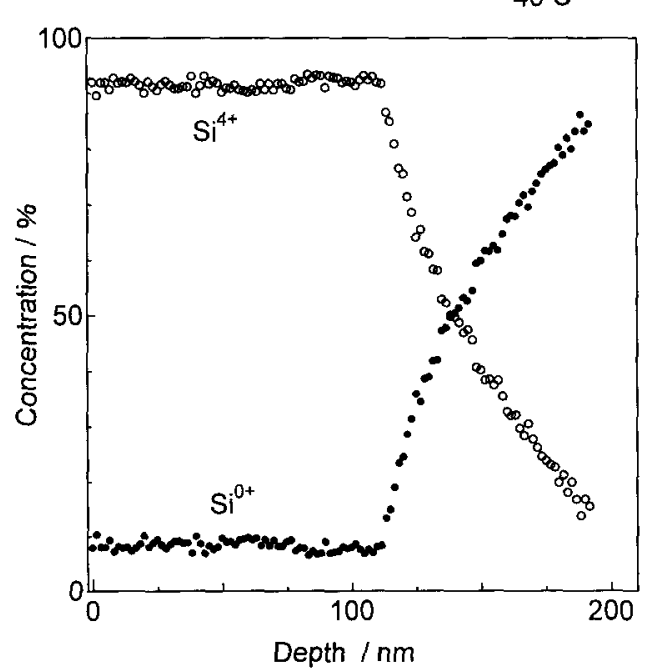

$50^{\circ} \mathrm{C}$

(e)

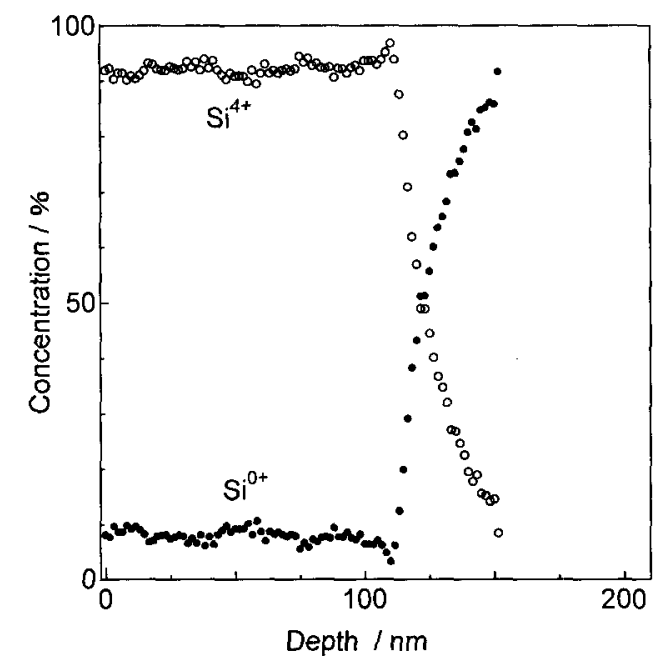

ambiguous at this moment.

The thickness and capacitance of the anodically oxidized films as a function of electrolyte temperature are given in Fig. 7. The former was determined by the rising point of $\mathrm{Si}^{0^{+}}$concentration in Fig. 5 and the maximum

$25^{\circ} \mathrm{C}$

(b)

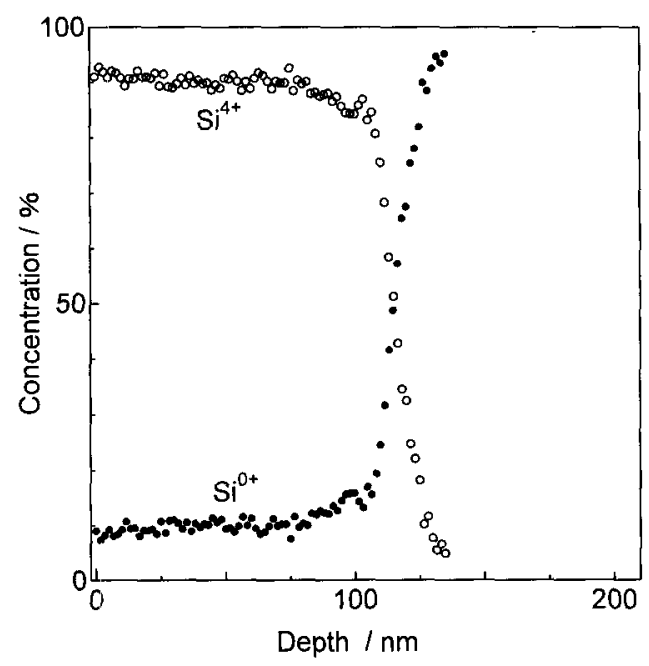

$45^{\circ} \mathrm{C}$

(d)

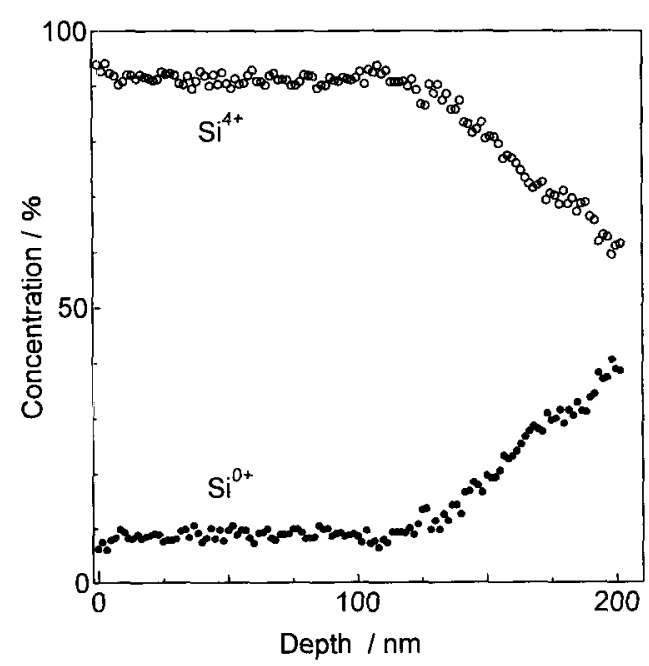

$60^{\circ} \mathrm{C}$

(f)

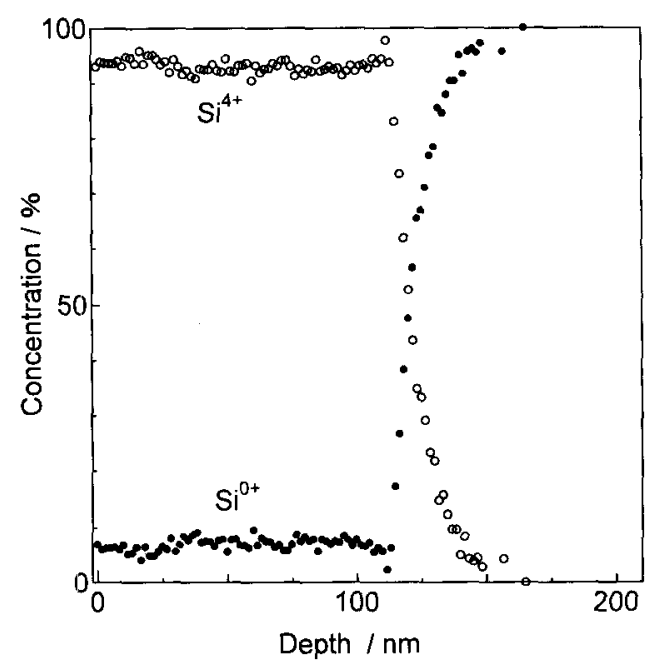

Fig. 5 Depth profiles of $\mathrm{Si}^{0+}$ and $\mathrm{Si}^{4+}$ concentration determined by XPS analysis. (a) thermal oxidation at $1100^{\circ} \mathrm{C}$, (b) anodic oxidation at $25^{\circ} \mathrm{C}$, (c) anodic oxidation at $40^{\circ} \mathrm{C}$, (d) anodic oxidation at $45^{\circ} \mathrm{C}$, (e) anodic oxidation at $50{ }^{\circ} \mathrm{C}$, (f) anodic oxidation at $60^{\circ} \mathrm{C}$. 
point of O1s in Fig. 6, both were close with each other, and the latter was determined by capacitance measurements on MOS structures fabricated from the anodically oxidized films. The thickness and capacitance are maximum and minimum when anodized at $45^{\circ} \mathrm{C}$ respectively.

$30^{\circ} \mathrm{C}$

(a)

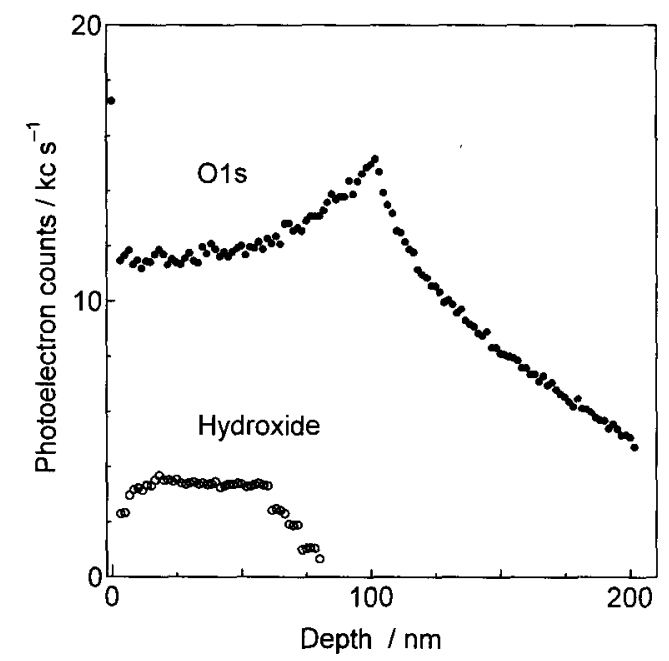

$40^{\circ} \mathrm{C}$

(c)

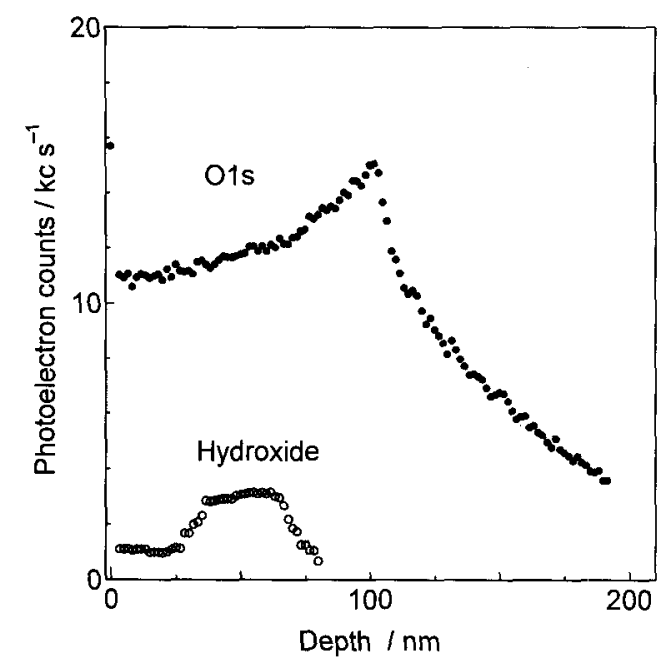

$50^{\circ} \mathrm{C}$

(e)

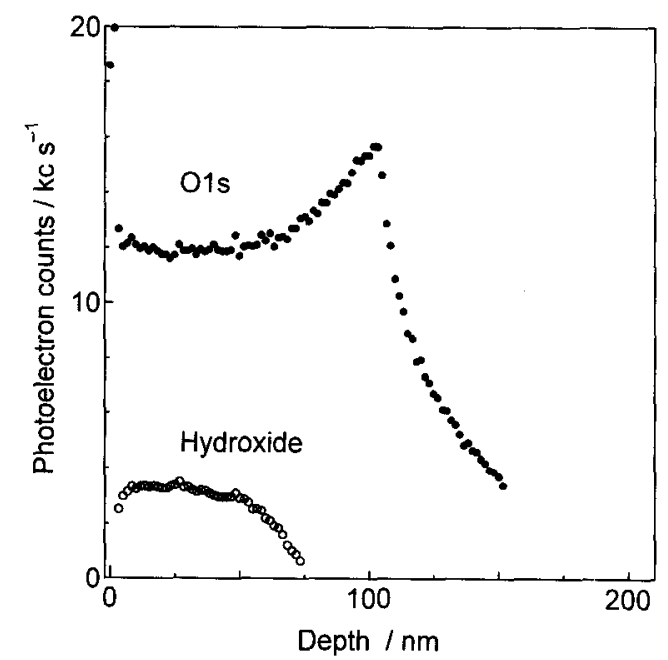

This is reasonable because the capacitance is inversely proportional to oxidize film thickness. In addition, a blue interference color on the surface of $\mathrm{Si}$ wafer was uniform under any conditions. The dielectric constant of films obtained from film thickness and capacitance may suggest

$35^{\circ} \mathrm{C}$

(b)

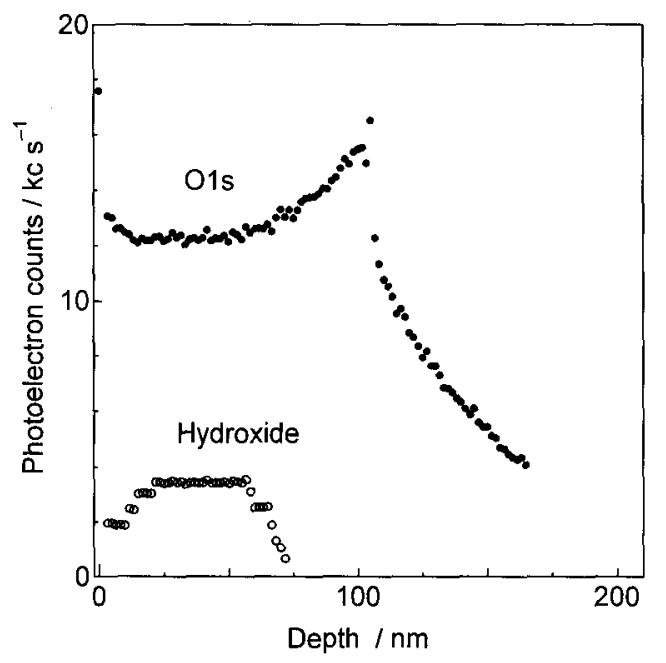

$45^{\circ} \mathrm{C}$

(d)

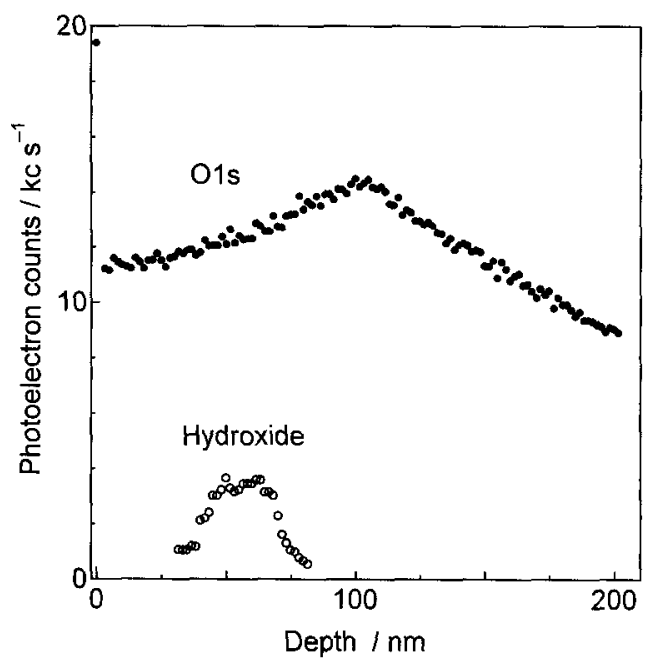

$55^{\circ} \mathrm{C}$

(f)

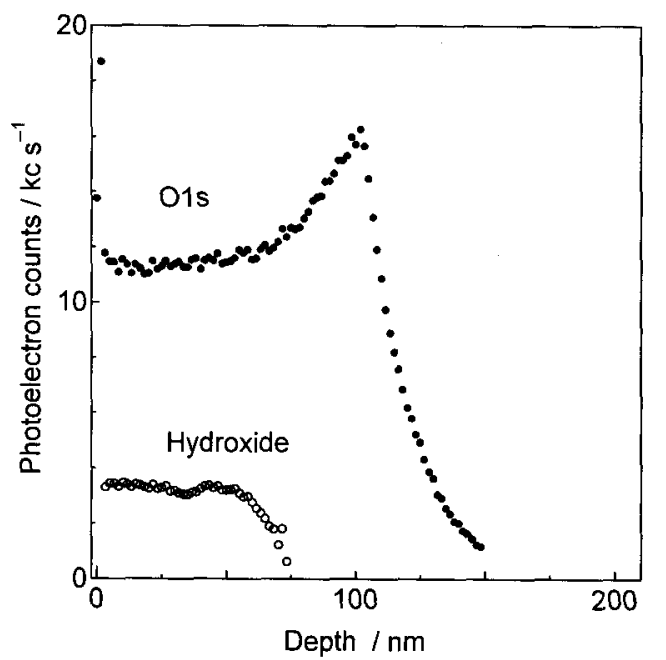

Fig. 6 Depth profiles of main 01s peak and 01s originated from oxygen in hydroxide determined by XPS analysis for anodic oxidation specimens. Anodic oxidation temperatures are as follows.

(a) $30^{\circ} \mathrm{C}$, (b) $35^{\circ} \mathrm{C}$, (c) $40^{\circ} \mathrm{C}$, (d) $45^{\circ} \mathrm{C}$, (e) $50^{\circ} \mathrm{C}$, (f) $55^{\circ} \mathrm{C}$. 


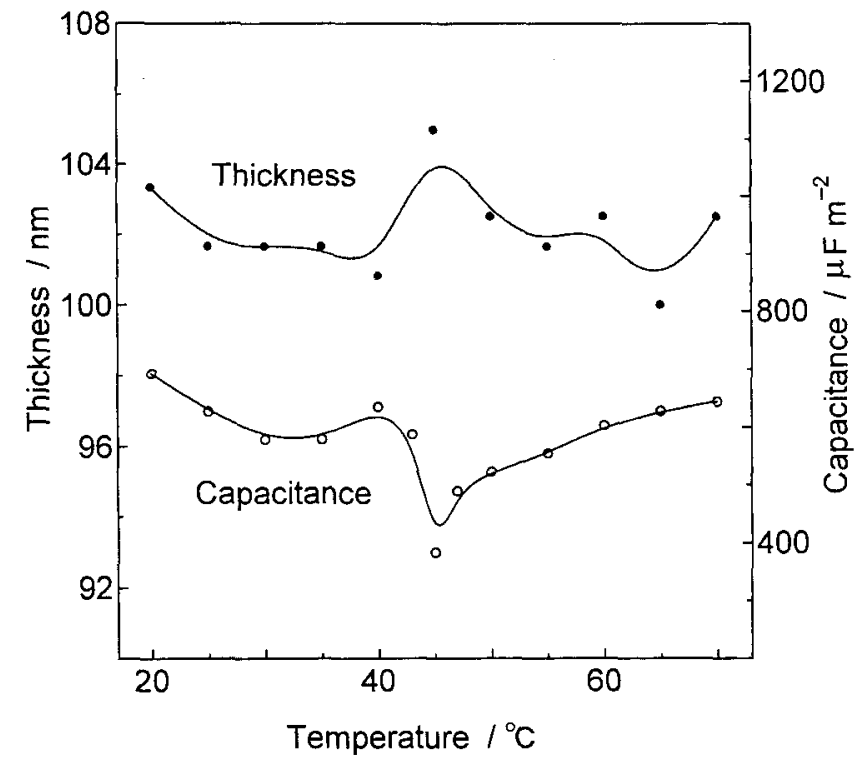

Fig. 7 Thickness and capacitance of the anodically oxidized films as a function of electrolyte temperature.

change in dielectric phase. This result also suggests that the film surface is flat and the measurements are correct. The results in Fig. 7 are consistent with those in Figs. 5 and 6.

In conclusion, the behavior of films anodically oxidized at $45^{\circ} \mathrm{C}$ may be explained as follows. Because of deterioration of insulating ability of $\mathrm{SiO}_{2}$ film, the film thickness increases and the transition time becomes long at this temperature. The film thickness is influenced by the amount of hydroxide in the film. Although the insulation property of the film oxidized at $45^{\circ} \mathrm{C}$ is not good, the film characteristics change greatly at about $45^{\circ} \mathrm{C}$. These results suggest that the film property can be controlled by the anodization temperature. Oxidized films of a good quality may be obtained by the anodization at a temperature higher than $45^{\circ} \mathrm{C}$.

\section{Conclusion}

The anodic oxidized of single crystalline silicon was carried out by applying a DC voltage in ethylene glycol solution at various temperatures. It can be concluded that the anodically oxidized film thickness has a maximum at the electrolyte temperature of $45^{\circ} \mathrm{C}$. The distribution of hydroxides inside the film, which was confirmed by XPS analysis, leans around the $\mathrm{SiO}_{2}-\mathrm{Si}$ boundary at the same temperature. The capacitance of anodically oxidized film had a minimum value at the electrolyte temperature of $45^{\circ} \mathrm{C}$. Changes in both the oxide film thickness and the transition time with electrolyte temperature depend on both the total amount and distribution of hydroxide in the film. The property of anodically oxidized films depends on the anodization temperature and is changed drastically at the vicinity of $45^{\circ} \mathrm{C}$, where the thickest oxide film is formed.

\section{References}

1) G. C. Jain, A. Prasad, and B. C. Chakravarty, J. Electrochem. Soc., 126, 89 (1979).

2) M. Croset and D. Dicumegard, J. Electrochem. Soc., 120, 526 (1973).

3) M. Seo, K. Fushimi, H. Takahashi, and K. Aotsuka, J. Electroanal. Chem., 368, 257 (1994).

4) M. Hall, M. F. Rau, and J. W. Evans, J. Electrochem. Soc., 133, 1934 (1986).

5) M. Yuga and M. Takeuchi, J. Korean Institute of Surface Eng., 32, 235 (1999).

6) M. Yuga, M. Takeuchi, and M. Oyama, J. Surface Finishing Soc. Japan, 50, 278(1999).

7) S. T. Ang and J. J. Wortman, J. Electrochem. Soc., 133, 2361 (1986).

8) H. F. Wolf, Silicon Semiconductor Data, Pergamon Press Inc., 549 (1976).

9) H. Hasegawa, S. Arimoto, J. Nanjo, H. Yamamoto, and H. Ohno, J. Electrochem. Soc., 135, 424 (1988).

10) P. C. Searson and X. G. Zhang, Electrochim. Acta, 36, 499 (1991).

11) E. F. Duffek, E. A. Benjamini, and C. Mylroie, Electrochem. Tech., 3, 75 (1965).

12) M. Yuga, N. Akazawa, T. Yamazaki, and M. Oyama, J. Surface Finishing Soc. Japan, 43, 335(1992). 